\title{
Generation of Monospecific Polyclonal Antibodies to Recombinant Filarial Antigen rWbL2 and Evaluation of Its Immunodiagnostic Utility in Filariasis
}

\author{
${ }^{1}$ Mahendra B Gandhe, ${ }^{2}$ Swapnali M Gandhe
}

\begin{abstract}
Introduction: Lymphatic filariasis is a mosquito-borne disease affecting nearly 120 million people across the world. Filarial antigen detection is a good indicator for mapping new filarial cases and for evaluation of filarial elimination programs as compared with the low sensitivity associated with the direct evidence of microfilaria (Mf) in blood samples. To overcome low sensitivity and night-time blood collection method for parasite detection in filariasis cases, the sandwich enzyme-linked immunosorbent assay (ELISA) was standardized for detection of circulating filarial antigen using monospecific polyclonal antibodies raised against recombinant filarial antigen rWbL2. In the present study, the specific antibodies raised against novel recombinant antigens rWbL2 were explored to develop suitable filarial antigen assays. It was possible to come out with a filarial antigen assay that could detect WbL2 or its equivalent antigen with $40 \%$ sensitivity (by using mouse anti-WbL2 antibody as capturing antibody), $60 \%$ sensitivity (using FSIgG human filarial serum immunoglobulin $\mathrm{G}$ as capturing antibody), and $100 \%$ specificity. These assays show promise to detect and monitor active filarial infection and thus prove to have potential as a useful diagnostic and monitoring tool in the elimination program.
\end{abstract}

Keywords: Enzyme-linked immunosorbent assay, Immunodiagnostic evaluation, Lymphatic filariasis, Recombinant filarial antigen, Wuchereria bancrofti.

How to cite this article: Gandhe MB, Gandhe SM. Generation of Monospecific Polyclonal Antibodies to Recombinant Filarial Antigen rWbL2 and Evaluation of Its Immunodiagnostic Utility in Filariasis. Indian J Med Biochem 2017;21(2):117-123.

Source of support: Nil

Conflict of interest: None

\section{INTRODUCTION}

Lymphatic filariasis is a mosquito-borne disease and a major public health problem affecting nearly 120 million

\footnotetext{
${ }^{1}$ Associate Professor, ${ }^{2}$ Senior Resident

${ }^{1}$ Department of Biochemistry, CCM Medical College, Durg Chhattisgarh, India

${ }^{2}$ Department of Dentistry, CCM Medical College, Durg Chhattisgarh, India

Corresponding Author: Mahendra B Gandhe, Associate Professor, Department of Biochemistry, CCM Medical College Durg, Chhattisgarh, India, Phone: +917694852825 , e-mail: drmahendragandhe@gmail.com
}

people across the world caused by Wuchereria bancrofti, Brugia malayi, and Brugia timori. In India alone, about 554.2 million people are reported to be at the risk of infection, with 27 million actually carrying Mf in blood and another 21 million suffering from clinical (CL) manifestations like hydrocele, lymphedema, and elephantiasis. ${ }^{1-3}$ The World Health Organization has launched the Global Programme for the Elimination of Lymphatic Filariasis (GPELF) and the target of the Global Programme is to eliminate lymphatic filariasis by the year 2020 through mass drug administration and alleviation of disability. ${ }^{4,5}$

The diagnosis and monitoring of filariasis has conventionally relied upon microscopic detection of Mf in peripheral blood, which is unreliable and lacks sensitivity. Further, the limitations associated with CL diagnosis, such as inconsistent symptoms and atypical manifestations seen in occult cases in the absence of Mf call for the need to develop suitable specific and rapid immunodiagnostic assays for control programs, particularly GPELF, and for mass surveys of community for filarial prevalence. ${ }^{6-8}$

Immunodiagnosis based on parasite antigen detection are considered to be very useful for the detection of active infection in filariasis. Extensive studies have been conducted to identify and isolate the filarial antigens of immunodiagnostic use. ${ }^{9}$ Though native antigens like Mf excretory-secretory antigens or purified somatic antigens have been shown to be quite useful for detecting circulating filarial antigen in bancroftian filariasis, one of the major problems is in the large-scale preparation of these antigens with consistent quality for bulk preparation of commercial diagnostic kits. ${ }^{10}$

Recently, by immunoscreening $W$. bancrofti complementary deoxyribonucleic acid libraries, novel recombinant filarial antigens rWbL2 have been identified to be reactive with different groups of filarial cases (Anandharaman et al. 2009 and Siva Prasad et al., unpublished observations). The WbL2 is a $W$. bancrofti $\mathrm{L}_{3}$ larval protein of the SXP / RAL-2 family protein. ${ }^{11}$ After specific expression of this WbL2 gene in the subventral pharyngeal gland, this protein secretion will occur.

In the light of the above facts, the present study was done to generate monospecific polyclonal antibodies to recombinant filarial antigen rWbL2 and comparatively 
evaluate their diagnostic utility to detect circulating filarial antigens in infected cases.

\section{MATERIALS AND METHODS}

\section{Human Sera}

Blood samples were collected from Mf individuals and patients with CL filariasis in Sevagram and surrounding villages in Maharashtra State, India, which are endemic for nocturnally periodic W. bancrofti. The presence of Mfs was checked by examining fresh night blood (collected between $9.00 \mathrm{pm}$ and $2.00 \mathrm{am}$ ) preparations. After informed consent, sera were collected from $25 \mathrm{Mf}$ patients and $25 \mathrm{CL}$ filariasis individuals manifesting hydrocele, lymphedema, and elephantiasis. Blood samples were also collected from 25 healthy individuals (EN-endemic normals), who had lived in a filarial endemic region for over 5 years and had no history of filariasis and from 15 students volunteers arriving at the Mahatma Gandhi Institute of Medical Sciences in Sevagram (at the time of their arrival) from places like Chandigarh, Kashmir, etc., where there is no filariasis (NEN-nonendemic normal). Sera were separated and stored at $-20^{\circ} \mathrm{C}$ with sodium azide as preservative.

\section{Expression and Purification of Recombinant Filarial Antigens rWbL2}

The recombinant gene constructs pRSET-B WbL2 were maintained in Escherichia coli host TOP10F, i.e., deficient in $T_{7}$ polymerase and, hence, the proteins were not expressed. For expression studies, the gene constructs pRSET-B WbL2 was transformed into BL21(DE3)pLysS, which contain a chromosomal copy of $\mathrm{T}_{7}$ ribonucleic acid polymerase, under the control of UV5 promoter and, hence, used for the expression of genes cloned under $T_{7}$ promoter. ${ }^{12}$ Cloned genes were induced with gratuitous inducers, such as isopropyl $\beta$-D-1-thiogalactopyranoside (IPTG) at a final concentration of $1 \mathrm{mM}$. Purification of recombinant proteins was done by immobilized metal affinity chromatography (IMAC).

\section{Generation of Monospecific Polyclonal Antibodies to Recombinant WbL2 Antigens in BALB/c Mice and Rabbits}

The BALB/c mice and rabbits were bred conventionally at our institutional animal house, which is registered with the Committee for the Purpose and Control of Supervision on Experimental Animals.

\section{Immunization Schedule}

Around 6 to 8-week-old BALB/c mice and rabbits of 1 year old were used for immunization with rWbL2 following standard immunization protocol as described by Catty and Raykundalia. ${ }^{13}$

Five BALB/c mice in each group were immunized intraperitoneally with $\mathrm{rWbL} 2$. The immunization schedule consisted of an initial dose of $15 \mu \mathrm{g}$ antigen in $100 \mu \mathrm{L}$ of 0.05 phosphate-buffered saline (PBS) emulsified in an equal volume of Freund's complete adjuvant. This was followed by three more booster doses of rWbL2 (15 $\mu \mathrm{g}$ each) emulsified in Freund's incomplete adjuvant at intervals of 7 days.

Two rabbits in each group were immunized with rWbL2 antigen following the schedule given below using Freund's complete (200 $\mu \mathrm{g}$ subcutaneous for first dose) or in incomplete adjuvants (for subsequent doses) as described in the protocol of Pocono Rabbit Farm and Laboratory Inc, Canadensis, Pennsylvania.

Sera were collected from mice/rabbits, prior to first dose and 3 days after the final dose of immunization schedule, from ear marginal veins of rabbit and from tail of BALB/c mice. Sera were separated and antibody titers were checked. The immunoreactivity of these antibodies (mouse and rabbit anti-rWbL2 antibodies) was tested against the purified $\mathrm{WbL} 2$ by Western blot, and the antibody titers were determined by ELISA.

\section{Preparation of IgG Fraction of Human Filarial Serum Immunoglobulin}

Human filarial serum immunoglobulin was prepared from $20 \mathrm{~mL}$ of pooled CL filarial serum by $33 \%$ saturation with ammonium sulfate followed by diethylaminoethyl cellulose ion exchange (Whatman DE52) chromatography as described by Reddy et al. ${ }^{14}$

\section{Detection of WbL2 or Its Equivalent Antigen in Circulation by Double Antibody Sandwich ELISA using Antibodies against Recombinant WbL2}

Double antibody sandwich ELISA was employed using different combinations of FSIgG or mouse anti-rWbL2 polyclonal antibodies as capture antibodies, and rabbit antibodies against rWbL2 as the probing antibodies to detect filarial antigen in sera. ${ }^{15}$

\section{Procedure}

The wells in polystyrene microtiter plates (NUNC, Denmark) were coated with $100 \mu \mathrm{L}$ of capture antibodies (FSIgG at $60 \mathrm{ng} / 100 \mu \mathrm{L} /$ well or mouse anti-rWbL2 antibodies at 1:1,000 dilution) in $0.06 \mathrm{M}$ carbonate buffer, $\mathrm{pH}$ 9.6 at $4^{\circ} \mathrm{C}$ overnight. The wells were washed one time with PBS Tween 20 (PBS/T) and then blocked with $100 \mu \mathrm{L}$ of $2 \%$ bovine serum albumin at $37^{\circ} \mathrm{C}$ for 1 hour. The wells were washed again three times with $0.01 \mathrm{M}$ PBS having $0.05 \%$ 


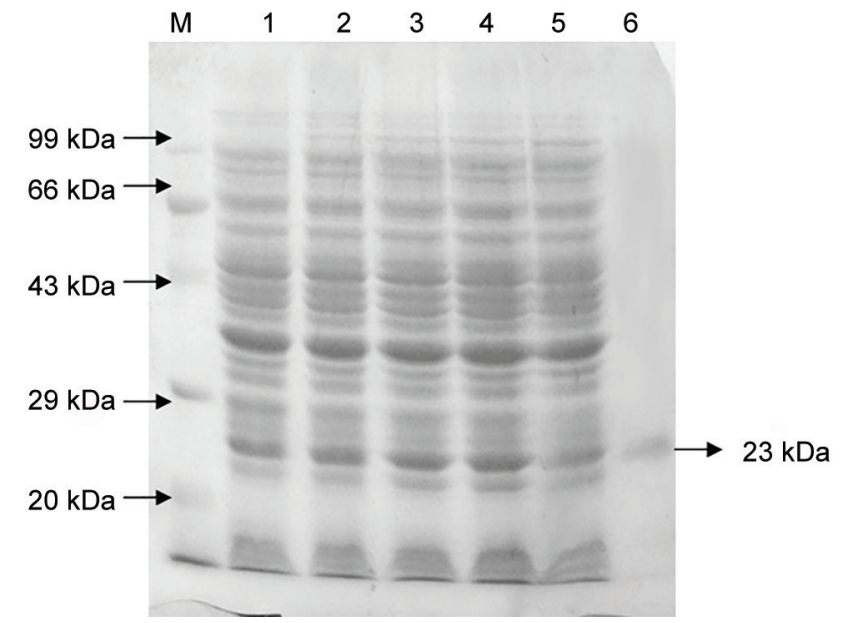

Fig. 1: The SDS-PAGE analysis of recombinant WbL2 (Lane MMolecular weight Marker, Lanes 1, 2, 3, 4-hours after induction, Lane 5-rWbL2 uninduced, Lane 6 —IMAC purified rWbL2 antigen)

Tween 20 at 1 minute interval and incubated each well with $100 \mu \mathrm{L}$ of optimally diluted sera $(1: 10)$ at $37^{\circ} \mathrm{C}$ for 1 hour. The wells were again washed three times at 1 minute intervals and further incubated with optimally diluted 1:10,000 probing antibody (rabbit anti-WbL2 antibody in PBS/T) at $37^{\circ} \mathrm{C}$ for 1 hour. After five washings with PBS/T, the wells were incubated with $100 \mu \mathrm{L}$ of optimally diluted $(1: 25,000)$ goat antirabbit horseradish peroxidase conjugate for 45 minutes. Following final washing, each well was incubated with $100 \mu \mathrm{L}$ of substrate consisting of tetramethylbenzidine $/ \mathrm{H}_{2} \mathrm{O}_{2}$ substrate as 1 in 20 dilutions in double distilled water for 15 minutes. Reaction was stopped by adding $50 \mu \mathrm{L}$ of $2 \mathrm{~N} \mathrm{H}_{2} \mathrm{SO}_{4}$. The results were read at $450 \mathrm{~nm}$ using ELISA reader. Sera samples showing absorbance value equal to or higher than the mean +2 standard deviation absorbance of NEN sera were considered as positive.

\section{Statistical Analysis}

Filarial antigen levels in different filarial endemic groups (25 in each group, i.e., Mf, CL, EN, and 15 in NEN) of filarial patients were analyzed using Statistical Package for the Social Sciences version 16.0 software and the tests of significance were tested at $\mathrm{p}<0.01$ and $\mathrm{p}<0.05$ by independent t-test.

\section{RESULTS}

\section{Generation of Monospecific Polyclonal Antibodies to Recombinant Filarial Antigen WbL2}

The gene constructs of pRSET-B WbL2 were transformed into E. coli BL21(DE3)pLysS cells and the cloned genes were induced with $1 \mathrm{mM}$ IPTG. The rWbL2 antigens were expressed as hexahistidine tagged proteins with molecular weights of $23 \mathrm{kDa}$ in sodium dodecyl sulfate

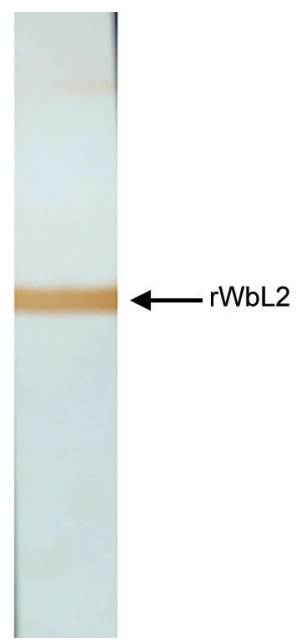

Fig. 2: Immunoblot analysis of rWbL2 with anti-His antibody

polyacrylamide gel electrophoresis (SDS-PAGE; Fig. 1). The same was confirmed by Western blotting using antiHis antibody as probe (Fig. 2). In the first part of the study, $\mathrm{rWbL} 2$ were expressed and used to immunize both rabbits and $\mathrm{BALB} / \mathrm{c}$ mice to raise antibodies. Immunization of $\mathrm{BALB} / \mathrm{c}$ mice and rabbits with $\mathrm{rWbL2}$ yielded high antibody levels. The immunoreactivity of these antibodies [rabbit and mouse specific anti rWbL2 antibodies] was tested against the purified rWbL2 by western blotting technique. The rabbit and mouse monospecific antisera against rWbL2 reacted only with the recombinant protein of $23 \mathrm{kDa}$ [ rWbL2 protein] and not with the vector protein (Fig. 1).

\section{Detection of Filarial Antigen WbL2 or Its Equivalent Antigen in Circulation by Sandwich ELISA with Antibodies to WbL2}

Preliminary experiments were carried out with mouse and rabbit anti-WbL2 antibodies to determine the choice of antibodies to be used as the capture antibody and the secondary antibodies as probing antibodies for standardization of ELISA. It was observed that the best results were obtained with mouse anti-WbL2 antibodies and FSIgG as the capture antibody and the rabbit antibodies as probing antibody.

By using mouse anti-WbL2 polyclonal antibody as capture antibody in double antibody sandwich ELISA, the mean filarial $\mathrm{WbL} 2$ or its equivalent antigen levels in sera of CLindividuals were significantly higher than the mean filarial antigen levels in NENs ( $<<0.05$; Graphs 1 and 2). A total of 10 of $25(40 \%)$ microfilaremic and 14 of $25(56 \%)$ CL filarial sera were positive for filarial WbL2 antigen by using mouse anti-WbL2 polyclonal antibody as capture antibody (Tables 1 and 2). Nine of the 25 endemic sera were found positive for filarial WbL2 antigen. None of the NEN sera was found positive for WbL2 antigen. 


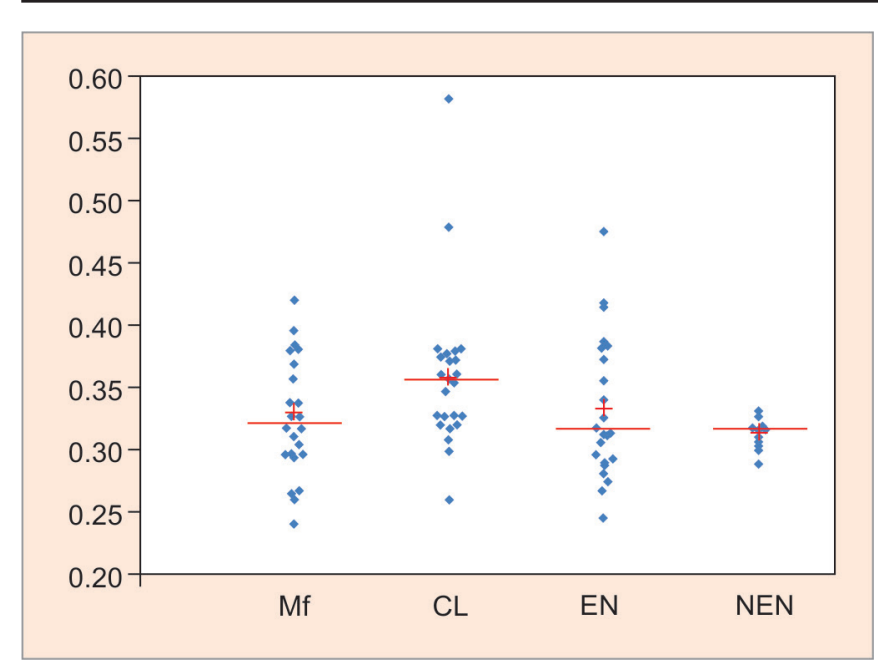

Graph 1: Scatter gram showing filarial WbL2 or its equivalent antigen levels in circulation in sera of different groups using mouse anti-rWbL2 antibody as capture antibody. Single dot indicates absorbance value in individual serum sample and solid line indicates mean value in each group. Mf vs NEN ( $p>0.05)$; CL vs NEN $(p<0.05)$; EN vs NEN $(p>0.05)$

Table 1: Detection of filarial WbL2 or its equivalent antigen using WbL2 antigen

\begin{tabular}{llll}
\hline & $\begin{array}{l}\text { Number } \\
\text { of sera } \\
\text { examined }\end{array}$ & $\begin{array}{l}\text { No. of individuals } \\
\text { positive using mouse } \\
\text { anti-rWbL2 as } \\
\text { capture antibody }\end{array}$ & $\begin{array}{l}\text { No. of individuals } \\
\text { positive using } \\
\text { FSlgG as capture } \\
\text { antibody }\end{array}$ \\
\hline Mf & 25 & $10(40 \%)$ & $15(60 \%)$ \\
CL & 25 & $14(56 \%)$ & $18(72 \%)$ \\
EN & 25 & $9(36 \%)$ & $1(4 \%)$ \\
NEN & 15 & $0(0 \%)$ & $0(0 \%)$ \\
\hline
\end{tabular}

By using FSIgG as capture antibody in double antibody sandwich ELISA, the mean filarial WbL2 or its equivalent antigen levels in sera of microfilariemic and $\mathrm{CL}$ individuals were significantly higher than the mean filarial antigen levels in NENs ( $\mathrm{p}<0.01$; Graphs 3 and 4$)$. A total of 15 of $25(60 \%)$ microfilariemic and 18 of 25 (72\%) CL filarial sera were positive for filarial WbL2 or its equivalent antigen using FSIgG as capture antibody (Tables 1 and 3). One of the 25 endemic sera was found positive and none of the 15 NEN sera were positive.

\section{DISCUSSION}

In the present study, rabbit and mouse antibodies raised against $\mathrm{rWbL} 2$ along with $\mathrm{IgG}$ of human $\mathrm{Cl}$ filarial serum (FSIgG) were explored in different combinations to standardize double antibody sandwich ELISA to detect circulating filarial antigen in sera of different filarial groups. The WbL2 is a W. bancrofti $\mathrm{L}_{3}$ larval protein of the SXP/ RAL-2 family protein. After specific expression of this WbL2 gene in the subventral pharyngeal gland, protein secretion will occur. ${ }^{11}$ The rWbL2 antigens were expressed as hexahistidine tagged proteins with molecular weights

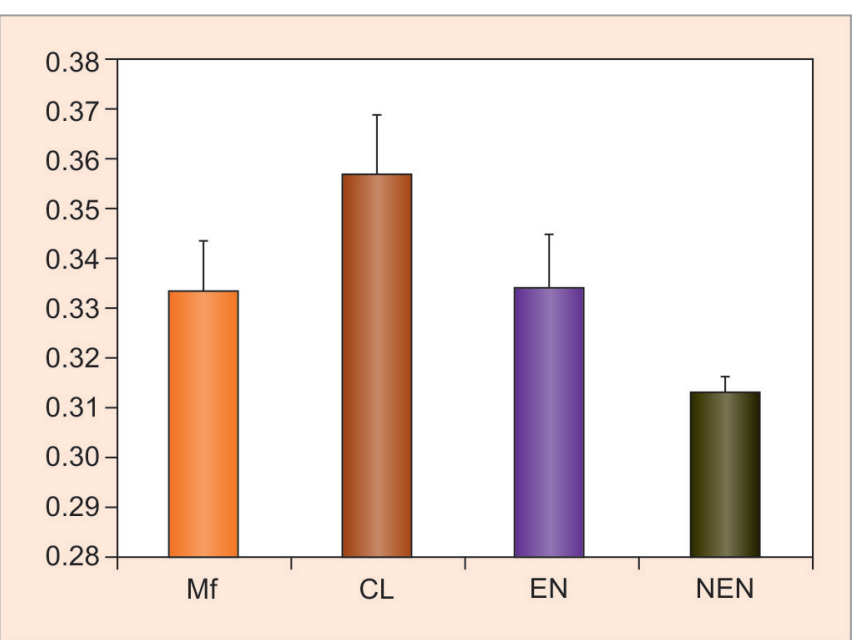

Graph 2: Levels of filarial WbL2 or its equivalent antigen in circulation in sera of different groups using mouse anti-rWbL2 antibody as capture antibody. Bars represent mean \pm standard error of mean absorbance values in each group. Mf vs NEN ( $p>0.05)$; CL vs NEN $(p<0.05)$; EN vs NEN $(p>0.05)$

Table 2: WbL2 or its equivalent circulating antigen detection using mouse anti-WbL2 as a capture antibody

\begin{tabular}{|c|c|c|}
\hline $\begin{array}{l}\text { Different } \\
\text { groups }\end{array}$ & $\begin{array}{l}\text { Number } \\
\text { of cases }\end{array}$ & $\begin{array}{l}\text { Absorbance of WbL2 or its equivalent } \\
\text { circulating antigen in each group } \\
\text { using mouse anti-WbL2 as a capture } \\
\text { antibody (mean } \pm \text { standard deviation) }\end{array}$ \\
\hline Mf & 25 & $0.3334 \pm 0.0531$ \\
\hline $\mathrm{CL}$ & 25 & $0.3567 \pm 0.0631^{*}$ \\
\hline EN & 25 & $0.3337 \pm 0.0551$ \\
\hline NEN & 15 & $0.3127 \pm 0.0123$ \\
\hline
\end{tabular}

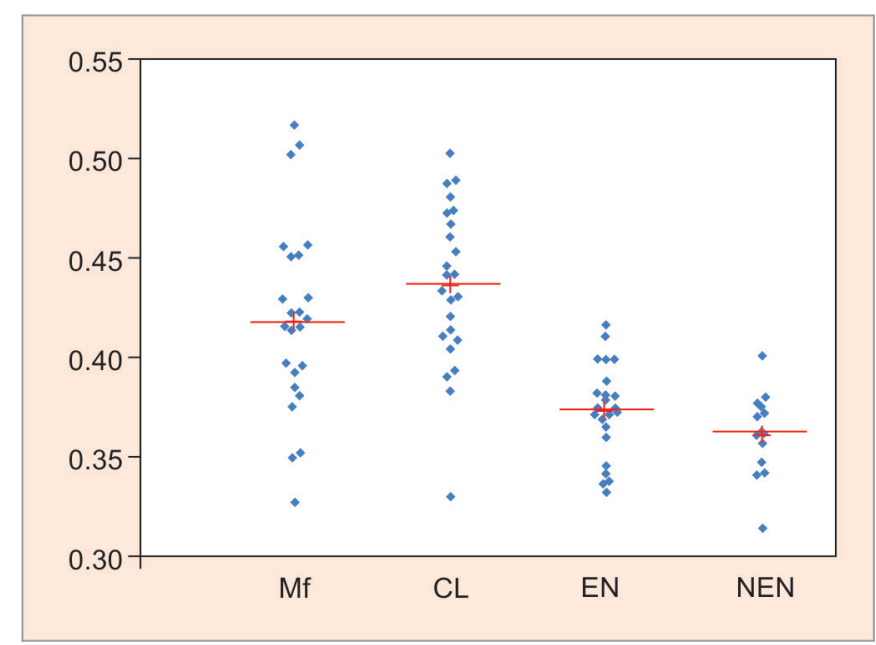

Graph 3: Scatter gram showing filarial WbL2 or its equivalent antigen levels in circulation in sera of different groups using FSIgG as capture antibody. Single dot indicates absorbance value in individual serum sample and solid line indicates mean value in each group Mf vs NEN $(p<0.01)$; CL vs NEN $(p<0.01)$; EN vs NEN $(p>0.05)$

of $23 \mathrm{kDa}$ in SDS-PAGE (Fig. 1). The same was confirmed by Western blotting using anti-His antibody as probe (Fig. 2). There is a similarity of WbL2 proteins with the other proteins of SXP/RAL-2 family, such as Ancylostoma 
Generation of Monospecific Polyclonal Antibodies

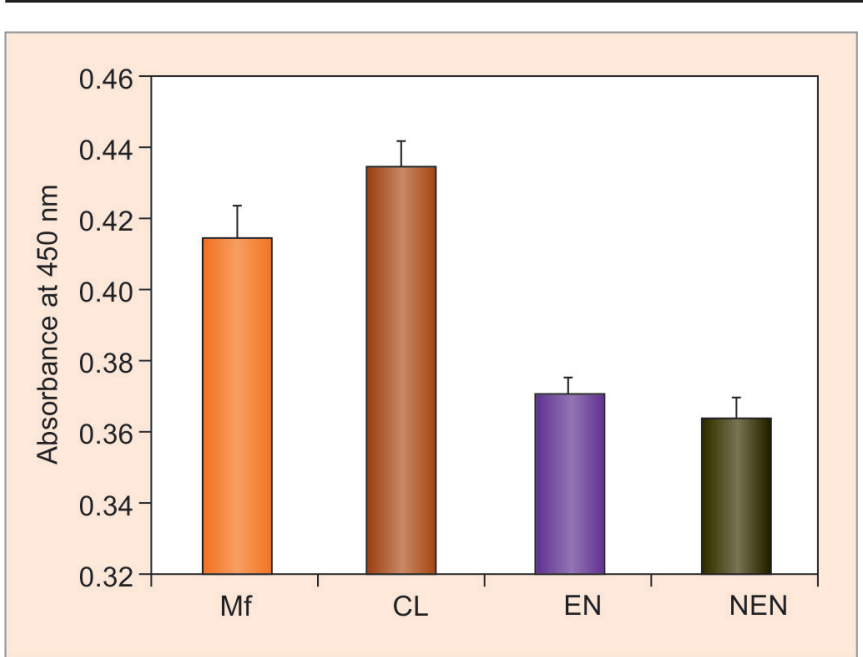

Graph 4: Levels of filarial WbL2 or its equivalent antigen in circulation in sera of different groups of human filarial sera using FSIgG as capture antibody. Bars represent mean \pm standard error of mean absorbance values in each group. Mf vs NEN $(p<0.01)$; CL vs NEN $(p<0.01)$; EN vs NEN $(p>0.05)$

Table 3: The WbL2 or its equivalent circulating antigen detection using FSIgG as a capture antibody

\begin{tabular}{lll}
\hline & & $\begin{array}{l}\text { Absorbance of WbL2 or its equivalent } \\
\text { circulating antigen in each group using }\end{array}$ \\
$\begin{array}{l}\text { Different } \\
\text { groups }\end{array}$ & $\begin{array}{l}\text { Number cases } \\
\text { of }\end{array}$ & $\begin{array}{l}\text { FSIgG as a capture antibody (mean } \pm \\
\text { standard deviation) }\end{array}$ \\
\hline Mf & 25 & $0.4156 \pm 0.0509^{* *}$ \\
CL & 25 & $0.4354 \pm 0.0399^{* *}$ \\
EN & 25 & $0.3719 \pm 0.0237$ \\
NEN & 15 & $0.3648 \pm 0.0240$ \\
\hline$* *$ p-value $<0.01$ highly significant
\end{tabular}

caninum (Ac-16), Ascaris suum (As14), Acanthocheilonema viteae (Av-RAL-2), Setaria digitata (Sd-SXP-1), Brugia malayi (Bm-SXP-1), and Onchocerca volvulus (Ov17 and P36991). This suggests that $\mathrm{WbL} 2$ may be having similar properties with these nematode-specific proteins. ${ }^{16}$ Some of the above proteins have been identified as a target vaccine candidate for protection from nematode infection upon immunization. One of the previous studies explored the antigenic properties of the SXP/RAL-2 family protein, and protective immune response elicited by these protein family against filarial and nematode infection. ${ }^{17}$

In our present study, the filarial antigen assay was standardized to detect WbL2 or equivalent antigen using FSIgG and mouse anti-WbL2 antibodies as capture antibodies. Both the antigen assays (based on FSIgG and mice anti-WbL2 antibodies) gave $100 \%$ specificity. However, using mouse antibodies, $\mathrm{WbL} 2$, or equivalent antigen could be detected only with $40 \%$ sensitivity (for microfilaremic cases). This assay also showed $56 \%$ of 25 CL filarial sera as positive (Table 4).

The best results for filarial antigen detection were obtained when the assay was configured to detect WbL2
Table 4: Performance characters of filarial antigen assay using rWbL2 antigen

\begin{tabular}{lll}
\hline & $\begin{array}{l}\text { WbL2 antigen detection } \\
\text { using mouse anti-rWbL2 } \\
\text { as capture antibody }\end{array}$ & $\begin{array}{l}\text { WbL2 antigen detection } \\
\text { using FSlgG as capture } \\
\text { antibody }\end{array}$ \\
\hline Sensitivity & $40 \%$ & $60 \%$ \\
Specificity & $100 \%$ & $100 \%$ \\
PPV & $100 \%$ & $100 \%$ \\
NPV & $50 \%$ & $60 \%$ \\
\hline PPV: Positive predictive value; NPV: Negative predictive value
\end{tabular}

or equivalent antigen using FSIgG as capture antibody. The assay detected filarial antigen with $60 \%$ sensitivity and $100 \%$ specificity (Table 4 ). The positive and negative predictive values were 100 and $60 \%$ respectively. Another positive aspect of this assay was that it detected $72 \%$ of CL filaria as positive, suggesting the presence of active filarial infection in these CL cases.

Immunological response studies on different $\mathrm{CL}$ categories of filarial patients have shown that Mf individuals have low Th1 response to filarial-specific antigens compared with CL filariasis cases and EN. Thus, more Mf individuals should be positive because of low clearance of antigen in antigen-based assay. In CL filariasis cases, there is more antigen clearance due to macrophage activation and increased Th1 response. ${ }^{18}$ Despite this fact, more CL cases tested positive for WbL2 antigens. The fact that the circulating $\mathrm{WbL} 2$ or equivalent filarial antigen could be detected in these CL cases and ENs even though they were negative for Mf in night blood smear suggests the presence of adult worms. This implies the presence of active infection in these cases. It is possible that some CL and EN group cases are from endemic areas, and they may be exposed to fresh infective bites of mosquitoes. In our study, the positivity for filarial antigen using the above assays varied from 4 to $36 \%$ in EN group. The EN is a very heterogeneous group in filaria-endemic areas, consisting of some which are truly negative and some with prepatent or unisexual infections.

The assay developed in this study has $100 \%$ specificity since sera from NEN were negative for circulating WbL2 antigen. The NEN groups of individuals were not exposed to infective mosquito bites and, hence, they are not filariainfection carriers. In our study, all NEN individuals were negative for WbL2 antigens in circulation.

In the present study, all the Mf cases with $W$. bancrofti infection were Mf positive. These assays were able to detect 40 to $60 \%$ microfilaremic individuals. Possible explanation for this low detection in Mf staged individuals could be that the level of WbL2 antigens in these samples could be very low and, hence, not detectable by this assay.

Hamilton et $\mathrm{a}^{19}$ explored the rabbit antibodies raised against $B$. malayi adult worm antigens. These are useful 
to detect filarial antigen in $W$. bancrofti microfilaremic cases. In the earlier report from this laboratory, polyclonal antibodies raised against $B$. malayi adult soluble antigens were shown to be useful for the detection of filarial antigen in 90 to $93 \%$ active microfilaremic infection and $30 \%$ CL filarial sera. ${ }^{20}$ Two commercially available kits employ monoclonal antibodies directed against animal filarial parasites, such as by ICT diagnostics (AMRAD, Australia) and the Trop Bio Test. The ICT filarial antigen card test (Binax) was devised by Weil et $\mathrm{al}^{21}$ by applying rapid immuno-chromatographic technique using specific polyclonal antibodies and $\mathrm{AD}$ 12.1 monoclonal antibodies attached to colloidal gold. Another monoclonal antibody raised against $O$. gibsoni adult antigen $(\mathrm{Og} 4 \mathrm{C} 3)$ by More and Copeman ${ }^{22}$ was found to be quite sensitive and specific to detect filarial antigen in $W$. bancrofti-infected cases. These kits are highly sensitive in detecting $\mathrm{mf}$ carriers in different geographical areas. ${ }^{23}$ However, these tests show poor sensitivity in detecting amicrofilaremic individuals with pathology and adult worm burdens. ${ }^{24}$

The IgG fraction of FSIgG has been used earlier in sandwich ELISA for the detection of filarial antigen in microfilaremic sera. ${ }^{14}$ Malhotra and Harinath ${ }^{25}$ used FSIgG and W. bancrofti mf ES antigen-penicillinase in microtiter plate inhibition ELISA and detected Mf ES antigen in $75 \%$ of microfilaremic sera, $28 \%$ of EN sera, and none of the NEN sera.

Lalitha et $\mathrm{al}^{26}$ have developed sandwich ELISA by using antibodies against recombinant antigens, BmSXP-1 and WbSXP-1, which have a detection of high proportion of Mf-positive cases with bancroftian filariasis in WbSXP-1 than BmSXP-1 assays. ${ }^{27}$

In the present study, the specific antibodies raised against novel recombinant antigens rWbL2 could be explored to develop suitable filarial antigen assays. It was possible to come out with a filarial antigen assay that could detect $\mathrm{WbL} 2$ or its equivalent antigen with $60 \%$ sensitivity and $100 \%$ specificity. However, comparison of these two sandwich assays with rWbL2, for detection of circulating WbL2 or its equivalent antigen, using mouse anti-WbL2 antibodies or FSIgG as capture antibodies showed the latter to have superior performance characters with 60\% sensitivity and $100 \%$ specificity to detect and monitor active filarial infection. Possible explanation for this low detection by using mouse anti-WbL2 as capture antibodies in Mfstaged individuals could be due to levels of WbL2 antigens in these samples being very low and, hence, not detectable by the assay. Sandwich assay with rWbL2 [for detection of circulating WbL2 or its equivalent antigen] using FSIgG as capture antibodies thus proved to have potential as a useful diagnostic and monitoring tool in the elimination program.
Hence, immunomonitoring along with CL examination of filarial-specific WbL2 antigen in circulation could be helpful in determining the appropriate period of DEC treatment for CL relief and cure, which are necessary for proper implementation of GPELF and to make world free of lymphatic filariasis. ${ }^{28}$

Though there are certain limitations, this assay for WbL2 or its equivalent antigen detection might be useful for epidemiological survey and detection of filariasis cases. In the present study, filarial-specific WbL2 or their equivalent antigen detections by using FSIgG as capture antibodies have been shown to be good immunological markers than detection of rWbL2 or their equivalent antigens using mouse anti-WbL2 antibodies.

\section{ACKNOWLEDGMENT}

Authors would like to thank to their guide Late Prof. Maryada Venkata Rami Reddy for his motivation and continuous support for the above research study during the postgraduate period.

\section{REFERENCES}

1. ICMR. Prospects of eliminating lymphatic filariasis in India. ICMR Bull 2002 May-Jun;32(5-6):1-14.

2. Alexander ND. Are we nearly there yet? Coverage and compliance of mass drug administration for lymphatic filariasis elimination. Trans R Soc Trop Med Hyg 2015 Mar;109(3): 173-174.

3. Modi A, Gamit S, Jesalpura BS, Kurien G, Kosambiya JK. Reaching endpoints for lymphatic filariasis eliminationresults from mass drug administration and nocturnal blood surveys, South Gujarat, India. PLoS Negl Trop Dis 2017 Apr;11(4):e0005476.

4. Jambulingam P, Subramanian S, de Vlas SJ, Vinubala C, Stolk WA. Mathematical modelling of lymphatic filariasis elimination programmes in India: required duration of mass drug administration and post-treatment level of infection indicators. Parasit Vectors 2016 Sep;9:501.

5. WHO. Eliminate Filariasis: Attack poverty - the global alliance lymphatic filariasis. Proceedings of the first meeting, 4-5 May 2000. Spain: WHO; 2000.

6. World Health Organization. Defining the roles of vector control and xenomonitoring in the global programme to eliminate lymphatic filariasis. Report of the Informal Consultation held at WHO/HQ, Geneva, 29-31 January 2002. Document WHO/CDS/CPE/PVC/2002. Geneva: WHO; 2002.

7. Ottesen EA. The global programme to eliminate lymphatic filariasis. Trop Med Int Health 2000 Sep;5(9):591-594.

8. Das PK, Pani SP, Krishnamoorthy K. Prospects of elimination of lymphatic filariasis in India. ICMR Bull 2002;32(5-6): 41-54.

9. Ganesh BB, Kader AM, Agarwal GS, Reddy MV, Harinath BC. A simple inexpensive dot blot assay using a $66 \mathrm{kDa} B$. malayi microfilarial antigen protein for diagnosis of filarial infection in an endemic area. Trans R Soc Trop Med Hyg 2001 Mar-Apr;95(2):168-169. 
10. Lammie PJ, Weil G, Noordin R, Kaliraj P, Steel C, Goodman D, Lakshmikanthan VB, Ottesen E. Recombinant antigenbased antibody assays for the diagnosis and surveillance of lymphatic filariasis - a multicenter trial. Filaria J 2004 Sep; 3(1):9.

11. Tytgat $T$, Vercauteren I, Vanholme B, De Meutter J, Vanhoutte I, Gheysen G, Borgonie G, Coomans A, Gheysen G. An SXP/ RAL2 protein produced by the subventral pharyngeal glands in the plant parasitic root-knot nematode Meloidogyne incognita. Parasitol Res 2005 Jan;95(1):50-54.

12. Sambrook, J.; Fritsch, EF.; Maniatis, T. Molecular cloning: a laboratory manual. 2nd ed. Cold Spring Harbor (NY): Cold Spring Harbor Laboratory Press; 1996.

13. Catty, D.; Raykundalia, C. ELISA and releated enzyme immunoassays. In: Catty D, editor. Antibodies Volume II: a practical approach. New York (NY): IRL Press at Oxford University Press; 1989.

14. Reddy MVR, Alli R, Devi KK, Narayan R, Harikrishnan R, Cheirmaraj K, Harinath BC. Comparative evaluation of microtitre plate peroxidase and stick penicillinase enzyme immunoassays for detection of filarial antibodies using Brugia malayi Microfiflarial Excretory-Secretory Antigen. J Parasitic Dis 1996;20:173-176.

15. Reddy MVR, Malhotra A, Harinath BC. Detection of circulating antigen in bancroftian filariasis by sandwich ELISA using filarial sera IgG. J Helminthol 1984 Sep;58(3):259-262.

16. Lustigman S, MacDonald AJ, Abraham D. CD4+-dependent immunity to Onchocerca volvulus third stage larvae in humans and the mouse vaccination model: common ground and distinctions. Int J Parasitol 2003 Sep;33(11):1161-1171.

17. García-Mayoral MF, Treviño MA, Pérez-Piñar T, Caballero ML, Knaute T, Umpierrez A, Bruix M, Rodríguez-Pérez R. Relationships between IgE/IgG4 epitopes, structure and function in Anisakis simplex Ani s 5, a member of the SXP / RAL-2 protein family. PLoS Negl Trop Dis 2014 Mar;8(3):e2735.

18. BalajiGanesh B,Parab PB,Katdare M, Reddy MVR, Harinath BC. A monoclonal antibody Bm Ab120 to $120 \mathrm{kDa}$ B malayi antigen with diagnostic potential in Bancroftian filariasis. J Parasit Dis 2004 Jun;28(1):29-36.
19. Hamilton RG, Hussain R, Ottesen EA. Immunoradiometric assay for detection of filarial antigens in human serum. J Immunol 1984 Oct;133(4):2237-2242.

20. Cheirmaraj K, Reddy MV, Harinath BC. Diagnostic use of polyclonal antibodies raised in mouse ascitic fluid in bancroftian filariasis. J Immunoassay 1990;11(4):429-444.

21. Weil GJ, Lammie PJ, Weiss N. The ICT filariasis test; A rapid format antigen test for diagnosis of bancroftian filariasis. Parasitol Today 1997 Oct;13(10):401-404.

22. More SJ, Copeman DB. A highly specific and sensitive monoclonal antibody based ELISA for the detection of circulating antigen in bancroftian filariasis. Trop Med Parasitol 1990 Dec;41(4):403-406.

23. Bhumiratana A, Koyadun S, Suvannadabba S, Karnjanopas K, Rojanapremsuk J, Buddhirakkul P, Tantiwattanasup W. Field trial of the ICT filariasis for diagnosis of Wuchereria bancrofti infections in an endemic population of Thailand. Southeast Asian J Trop Med Public Health 1999 Sep;30(3):562-568.

24. Nguyen NL, Plichart C, Esterre P. Assessment of immunochromatographic test for rapid lymphatic filariasis diagnosis. Parasite 1999 Dec;6(4):355-358.

25. Malhotra A, Harinath BC. Detection and monitoring of microfilarial ES antigen levels by inhibition ELISA during DEC therapy. Indian J Med Res 1984 Feb;79:194-198.

26. Lalitha P, Eswaran D, Gnanasekar M, Rao KVN, Narayan RB, Scott A, Nutman T, Kaliraj P. Development of antigen detection ELISA for the diagnosis of Brugian filariasis and Bancroftian filariasis using antibodies to Recombinant filarial antigens BmSXP-1 and WbSXP-1. Microbiol Immunol 2002 Feb;46(5):327-332.

27. Rao KV, Eswaran M, Ravi V, Gnanasekhar B, Narayanan RB, Kaliraj P, Jayaraman K, Marson A, Raghavan N, Scott AL. The Wuchereria bancrofti orthologue of Brugia malayi SXP-1 and the diagnosis of bancroftian filariasis. Mol Biochem Parasitol 2000 Mar;107(1):71-80.

28. McCarthy JS, Guinea A, Weil GJ, Ottesen EA. Clearance of circulating filarial antigen as a measure of microfilaricidal activity of diethylcarbamazine in Wuchereria bancrofti infection. J Infect Dis 1995 Sep;172:521-526. 